"Mix equal parts of $\mathrm{A}$ and $\mathrm{B}$, and allow the plate to soak in the mixture for ten minutes or a quarter of an hour, in the dark. Wash well.

"(3) Transfer the washed plate to a solution of three oz. of sodium hyposulphite in $20 \mathrm{o} z$. of water. Allow it to remain for half an hour, and then wash the plate in running water for three hours.

"(4) Prepare a 'clearing' solution according to the following formula :-

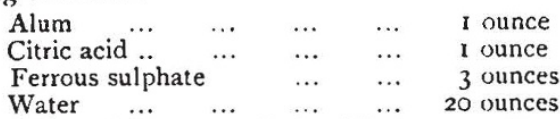

"Allow the plate to soak in this for ten minutes, and then remove and wash in running water for six hours.
"The sulphocyanıde and gold solution has the property of precipitating gold on the image, and rendering it of a blacker colour and diminishing the chance of fading. I should think you will find it useful always to use the clearing solution and the sulphocyanide and gold solution in your usual process." WILLIA.M J. S. LOCKYER.

\section{VIBRATION OF GUN-BARRELS.}

THIS research on the vibration of gun-barrels is a continuation of former investigations on the nature of vibrations set up in a gun-barrel when fixed, with a view to discover how the error of departure is affected by rapid oscillations of the barrels when firmly clamped. The authors' experiments were made on three small-bore

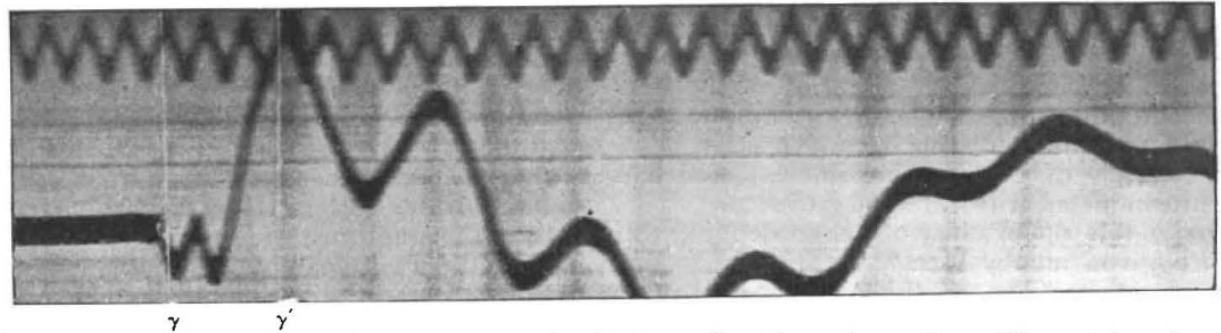

FIG. r. $-3 \mathrm{~mm}$. Cal. Run clamped in cork support. Vibration curve of a point at the muzale. $\gamma$ Disengaged ipark at the instant at which the shot leaves the muzzle; $\gamma^{\prime}$ Iisengaged spark at $4{ }^{\circ} \mathrm{s}$. distance from the muzple. In the unconstrained method of holding the weapon, the amplitude of the vibration is not so strongly marked as when it is clamped. (See Fig. 2.)

“(5) Prepare in advance two solutions, C and D. So'ution C. Ammonium sulphoSoluti in I).
(iold chloride ........... $15 \mathrm{gr}$. Water..... $100 \mathrm{gr}$. Water ................... $15 \mathrm{oz}$

"For use take $I$ ounce of each, and add $\delta$ ounces of water. Soak the plate in this mixture for ten minutes, and at the end of the time remove and wash it in running water for half an hour. Transfer to a dish of distilled water, where it may remain for an hour. Finally, drain on blotting-paper, and allow to dry.

"The separite solutions, A, B, C and D, will keep for an indefinite tim?, and the same may be said of the rifles, placed at their disposal by the firm of Mauserviz., one $8 \mathrm{~mm}$. experimental rifle furnished with a wood stock, one $7 \mathrm{~mm}$. Spanish model, and one trial gun $6 \mathrm{~mm}$. -in all cases smokeless powder was used. In their early experiments the rifles were clamped firmly when fired, but in their recent work this method of support was abandoned, as they found that the clamping imposed restraints which altered the character of the shooting of the rifles and also their mode of vibration. 'This is by no means a new discovery. The late W. E. Metford, of well-known rifle repute, showed long ago $(1870)$ that the shooting of a rifle was greatly changed when the barrel was securely clamped to a heavy mass of iron. In order

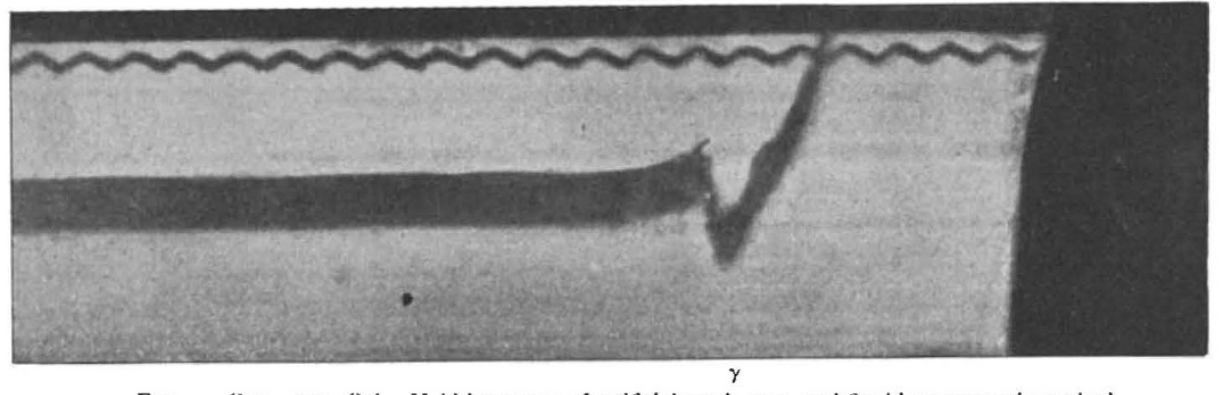

Fig. 2.-Gun $7 \mathrm{~mm}$. Cal. He:d hy means of artificial marksman, and fired by pneumatic method.

clearing solution, if kept tightly corked. But when mixed together they will not keep, so fresh mixtures should be made each time.

"I have given you the full process adopted on the plates you sent me, but I think some of them may be omitted with no disadvantage. For example, I should like to try if the soaking in hyposulphite may be dispensed with. I think it can, but I only tried leaving it out on the plates you sent that had not faded.

"I always found the great secret of preventing images from fading out was to wash them very well in running water. The clearing solution allows the time of washing to be a little shortened, but not much.

No. 1629, voL. 63$]$ to avoid this source of trouble the experimental guns were sometimes embedded in cork and sometimes suspended pendulum fashion by ropes, so that they were practically unrestrained and the condition of support approximated to the normal one, namely, the rather free support of the hands and shoulder of the marksman. The movements of the barrels were recorded by means of photography on a moving sensitive plate. Two methods were employed for firing the guns, viz., an electro-magnetic trigger-puller, and a pneumatic method in which a small piston, moving in a cylinder attached to 1 "Untersuchung über die Vibration des Gewehrlaufes." Von C. Cranz unld K. R. Koch. Pp. $23 ; 4$ plates. (München, 1900.) 
the trigger-guard, moved the trigger. This pneumatic method was employed by the authors of the paper because it introduced no vibration when acting, and the method is strongly emphasised by the writers, who apparently have overlooked the fact that an exactly similar method has been in use in England for the last seven years in connection with the Tram chronograph used in ballistic work. Since the pneumatic method of firing introduces no vibration, it could be used in connection with a gun slung by ropes.

An attempt is made to show nodal points of vibration by means of sand figures, after the manner of Chladni, and sand curves were produced on a surface attached by cement to the guns when clamped and also when supported loosely, and also in the case of a barrel used without a stock. The vibrations appeared to be approximately the same in each case. 'The research concludes with a list of results, and it is stated that in the case of the $6 \mathrm{~mm}$. gun the exit of the shot takes place just before the completion of the first quarter vibration of the first appearing second over tone. The research, although presented in a form almost too much condensed in parts to be quite clear, is of considerable interest, and has evidently been conducted with care and patience.

I wish to take this opportunity of acknowledging the kind assistance given ne by Mrs. Max Schiller in connection with some portions of the authors' work on ballistics.

F. J.-S.

\section{THE ROYAL INIIAN ENGINEERING COLLEGE.}

$T T$ is evident from the letters and comments which $I$ have appeared in the Times and other papers, that the summary notice of dismissal of a large part of the scientific staff of the Royal Indian Engineering College, Coopers Hill, is regarded as an act of injustice which, if permitted to take effect, would be distinctly detrimental to the interests of science. The facts of the case were stated in these columns last week, and an examination of them is sufficient to convince any one that the seven gentlemen who have received notice that their services will not be required after the end of the Easter term have been treated with little courtesy and no consideration. That it should be possible for men of scientific eminence to be dismissed from their posts more easily than if they were civil service messengers or clerks, is one of the many indications we have of the small value attached by the official mind to scientific work and dis. tinction. Perhaps Lord Kelvin's letter, which we reprint below from the rimes, will show that the matter is not to be permitted to rest in its present unsatisfactory position.

Sik,-The correspondence which appeared in the Times of January 3 regarding Coopers Hill College has caused a painful shock to all who know of the good work which the college has done in giving to India the benefits of well-trained engineers in the service of its Government. No one can read that correspondence, I believe, without being convinced that the seven professors and teachers whose position is threatened are justified in asking for an inquiry.

The proposed action-a sudden and arbitrary dismissal of able and distinguished scientific teachers who have been doing duty for periods of nine to thirty years in a satisfactory manneris certainly not to be expected in institutions under the control of the British Government; and I sincerely hope that the Secretary of State for India in Council will see his way to granting the request for an inquiry.

I am your obedient servant,

Netherhall, Largs, Ayrshire, January i I.

KEININ.

The principle of the action is as bad as the private injury, for it suggests that gentlemen of education and distinction, who have held Government posts for long periods, may have their services dispensed with at the will of a military officer having no special qualifications to enable him to know the value of their work. If there is no more security of tenure for scientific men than is implied in the act of the president of the College at Coopers Hill, it is because they have not asserted their rights with sufficient insistence, and the sooner they do so the better it will be for their positions. Opportunity for showing that the gentlemen who have been instructed to give up their appointments at Coopers Hill have the world of science behind them will be afforded by a memorial in their favour which we hear is being prepared, to be submitted to the Secretary of State for India.

No excuse worthy of consideration has been offered for the dismissal of half the educational staff of the College. The salaries of the gentlemen who have received notice - - for that is what it amounts to-are by no means too liberal, so that the statement that the action has been taken with a view of reducing expenses seems altogether insufficient. As "M. A." shows in the Times, money is available for the needs of the College, and "it is the worst form of economy to starve the staff of a teaching institution." Another writer goes even further, for he asks, "Is it not the case that the college has been for some years selí-supported by fees from students?" But, putting this question aside, we have no hesitation in say. ing that the work done by the gentlemen dismissed could not be carried on with the present efficiency at less cost. In any case, the method adopted is not the one best calculated to improve the efficiency of any institution.

There is one other point, and it is not the least important. Assuming that the president of the College is able to dismiss arbitrarily as many members of the staff as he cares to dispense with, then some substantial compensation should be given to those thus compulsorily retired. Dr. Jolnstone Stoney mentions in the Times that "when, twenty-one years ago, the Government through Parliament gave Ireland an Examining Board in place of a Cniversity, it allotted when doing so the full amounts of their salaries or emoluments as compensation for loss of office to the outgoing members of the staff of the late Queen's University and to those professors of the University who were required by their statutes to discharge University as well as college duties." This principle should be brought to the front and urged upon all who have the control of institutions like that at Coopers Hill, namely, that adequate compensation for loss of office must be awarded to the inembers of the staff who have to retire after years of good service.

\section{NOTES.}

Sir Arcinibali) Geikie will shortly retire from his post of Director-General of the Geological Survey of the United Kingdom. He will be entertained by his friends at a com. plimentary dinner early in March. All who wish to attend should communicate with Mr. F. W. Rudler, Museum of Iractical Geology, 28, Jermyn Street, London, S.W.

THE death is announced, at seventy-eight years of age, of Prof. Hermite, the eminent French mathematician. He was a member of the Academy of Sciences and a Foreign Member of the Royal Society. Announcement is also made of the death of M. Chatin, the botanist, and a member of the Paris Academy of Sciences.

THE Geological Society will this year award its medals and funds as follows:--The Wollaston medal to Mr. Charles Barrois, of Lille; the Murchison medal to Mr. A. J. Jukes-Browne, of Torquay; the L,yell medal to Dr. R. H. Traquair, of Edin. burgh; and the Bigsby medal to Mr. G. W. Lamplugh, of the (jeological Survey. The Wollaston fund goes to Dr. A. W. Rowe, the Murchison fund to Mr. T. S. Hall (Melbourne), and ; the Lyell fund to Dr. I. Wr. Evans and Mr. A. McHenry. NO. 1629 , voL. 63] 